\title{
TWO CASES OF IDIOGLOSSIA.
}

\author{
WITH PHONOGRAPHIC DEMONSTRATION OF THE \\ PECULIARITY OF SPEECH.
}

\author{
BY \\ W. HALE WHITE, M.D., \\ PHYSICIAN TO GUY'S HOSPITAL; \\ AND \\ C. H. GOLDING-BIRD, F.R.C.S.,
} SENIOR ASSISTANT SURGEON TO GUY'S HOSPITAL.

Received December 3rd, 1890-Read March 10th, 1891.

THe younger of the two cases which we show this evening to the Fellows of this Society was brought to one of us, in September, 1889, for an opinion as to his future education, it being believed by his friends that the defect in speech which we have to bring under notice to-night was a form of deaf mutism.

That this was not the case was at once apparent, the child's hearing, as well as his appreciation of what was said to him, being perfect; and he clearly was able to express himself in articulate sounds, which-and herein was the peculiarity of the case-it was impossible to understand.

The boy had recently been rejected by an asylum-school under the impression that he was dumb, and it was suggested that his was a suitable case for the Deaf and Dumb Asylum. 
Although we show this evening two brothers, both similarly affected but in varying degree, there is also a sister, who is older than either of them, who is slightly affected in the same way.

These three children are the offspring of the same parents, who are English, without admixture of any foreign blood. They have never been used to hear a foreign language spoken. Their father is dead. He is said to have spoken badly and to have stammered; it is also said that he cured himself at the age of twenty by some American process. He died at fifty. His mother was in a lunatic asylum. A paternal uncle of these children is said to have talked indistinctly many years ago, but now he speaks distinctly. Their mother is a nervous emotional woman.

We will now describe each of these children in detail, taking first the youngest, Alfred, who is the most affected, and was the child first introduced to us. In our description of him we shall present to the Society a picture of the characteristics of this remarkable infirmity, hitherto. unnamed, and as far as we are aware, but imperfectly studied.

Alfred James P - was first seen in September, 1889, at the age of nine years. He had been educated between the ages of five and nine in dames' schools, where he had acquired a character for sharpness and ability, and also an amount of learning reasonably proportionate to his age and station. The mistress of his school had, however, observed that his speech was incomprehensible, and she specially tried to improve his articulation, but failed to do so, and expressed her opinion to his friends that he was tongue-tied, or that his tongue was too short. His mother, on being questioned by us in regard to this matter, said she had observed the same peculiarity since he first began to speak, but she had not troubled herself about it. Both she and the mistress were convinced that he understood all that was said to him, but he failed to express himself in intelligible words to them and his juvenile companions. 
When first seen by us the child was, as now, healthy, and except for his speech, perfectly normal. He is intelligent and well educated for his position; he can do simple sums, read to himself, and write well from dictation. His orthography is correct. No physical defect is discoverable, and his tongue and larynx are normal in form and action. He is right-handed; his viscera are not transposed; there is no facial hemiatrophy; and he does not stammer.

Directly he was spoken to it was evident that he was not like other children. His intonation and mode of articulation were perfect, but he employed sounds to express his words which were unlike those of English, or of any language known to us. If he were speaking at such a distance that one was not surprised at being unable to catch every word, his speech gave the impression, by the regular inflexion of his voice and the occasional repetition of the same sounds, that it was the speech of someone conversing intelligently in an unknown tongue. In close conversation the same impression held, but the strange sounds that he uttered soon showed that he was speaking a language entirely his own. He was asked to read an article from the newspaper, and he did so with a properly modulated voice as though he understood it, but what he said was quite incomprehensible. Reading it the second time he exactly reproduced the same sounds to express the various words.

Questioned upon what he had read, he convinced us that he quite understood the meaning of the article. Besides, we have had frequent opportunities of observing that he can enjoy an amusing book as well as any other child.

It would have been impossible to convey to the Society any idea of the language of the child as we first heard him, but for the phonograph; and our ability to demonstrate by means of this instrument, the condition of his speech more than a year ago, is due to the courtesy of the Phonograph Company. 
We have attempted in Table $I$ to show the peculiar articular sounds, simple and combined, which he used to express the words and syllables of our language.

\section{TABLE I.}

(A) Alphabet as pronounced by Alfred P-. When not otherwise indicated the letters have their usual value.

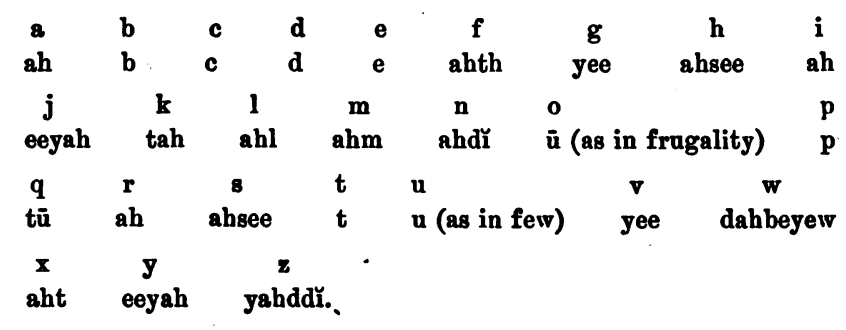

(B) The Lord's Prayer as pronounced by Alfred P-.

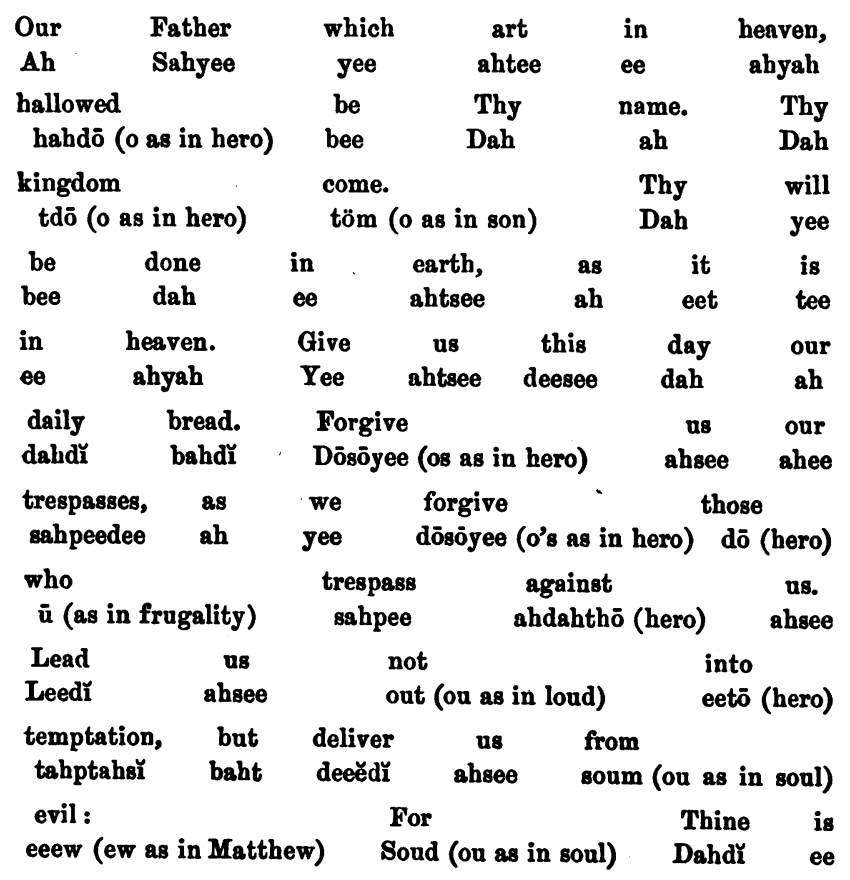


IDIOGLOSSIA.

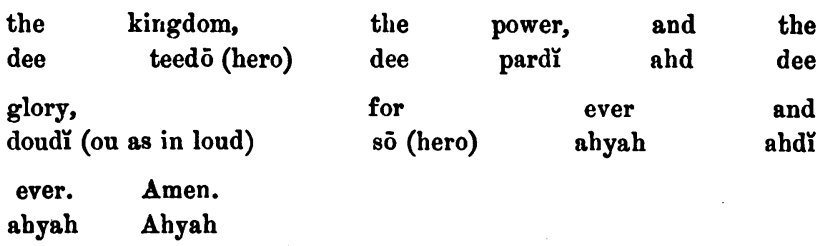

We will specially draw attention to the following points which have struck us during frequent interviews with this child.

(A) He always employs the same sounds or combination of sounds to express aloud any given syllable or word in our language, and however often he is asked to repeat it he always employs the same sound or combination of sounds. Inasmuch as this peculiarity constitutes the essential feature of this kind of case, and inasmuch as he thus always speaks a language of his own, we would venture to suggest the word "idioglossia" as a good name for this condition.

(B) His language is so bizarre that any detailed criticism with the idea of classifying the method by which he seems to be guided in his expression of words is beyond us, yet we observe besides the facts insisted on in the former paragraph he uses the word "sahpee" to express "trespass" and "sahpeedee" to express "trespasses," thus suggesting a primitive attempt at inflection. Also the initial "th" seems invariably to be transformed into " $\mathrm{d}$," but this is a common defect in children.

(c) This idioglot language is in this lad almost musical. It flows easily from his lips, and, as will be seen by reference to the table, he makes frequent use of his liquid sounds $(l, m, n, r)$ and his vowel sounds; for example, "heaven" is "ahyah," "hallowed" is " hahdo,", and the closing words of the Lord's prayer also illustrate this fact.

(D) He does not appear to employ true gutturals, and this adds force to our last remark.

We have already mentioned that he writes English correctly to dictation, and this is most remarkable considering the hopeless jargon of his spoken language. 
We have illustrated by the phonograph and described the condition of the child sixteen months ago, and although his speech has much improved the defect is still very evident.

The treatment that has been carried out under our suggestion has been not only careful and constant tuition in articulation, but isolation as far as possible from anyone who would not constantly correct his mistakes; he has also been separated from his brother and sister.

Robert J. P. P-, æt. $10 \frac{1}{2}$, was educated at the same schools as his brother from the age of five to nine, and his defect of speech has been present ever since he began to talk. He has always seemed an intelligent lad. He has acquired the same degree of education as his brother. He like his brother speaks a language of his own, but writes correctly to dictation.

It will be seen on reference to Table II that the peculiarity of his speech is less marked than in the case of his brother, and he uses the guttural letters. This lad can be to some extent understood when he speaks, and all we have said of his brother's condition applies to him, though in less degree. Physically he is as sound as his younger brother, but it is noticeable that he is left-handed, and in writing he is almost ambidextrous.

\section{TABLE II.}

(A) Alphabet as pronounced by Robert J. P. P-. Unless otherwise indicated the letters have their usual value.

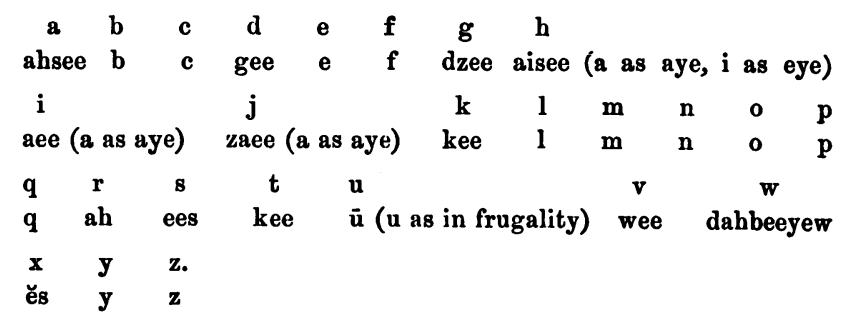


(B) The Lord's Prayer as pronounced by Robert J. P. P-. The words are spelt in their usual manner when he pronounced them as ordinary persons do.

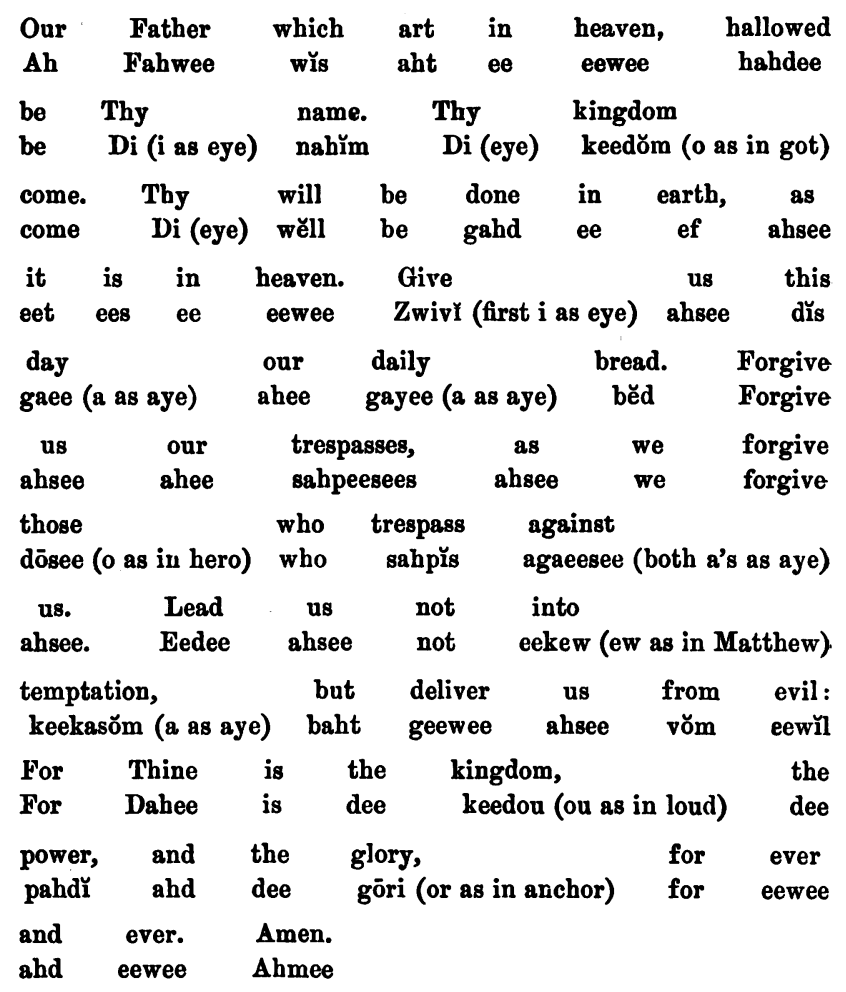

On making this boy say the elementary sounds, we obtained the following results : He said āi for $\hat{e}, w$ for $\nabla$, $k$ for $t, g$ for $d, f$ for $t h, d$ for $\delta, n$ for $n g$; o was impure, 1 at the beginning of a word was dropped, but the final 1 was correct; $r$ was quite incomprehensible, all double consonants were difficult; $p, b, f, k, g, m, n, s$, and $z$ were all correct. He was very bad at combining sounds to form words.

The speech of the sister, Alice $\mathrm{P}$-, æt. about 14 years, like that of many other children, is only slightly defective. 
Her defects are, she employs $v$ and $f$ for "th," and drawls out some words, as "quarter," which she pronounces "keyoughtter." She is right-handed, but can write fairly well with the left hand. She is physically perfectly healthy.

All these children have been brought up together. They can understand one another after a fashion better than either of us can understand them. In a case quoted by Romanes, the reference to which we give later, a child aged $4 \frac{1}{2}$ years was the subject of idioglossia, but her younger brother was able to converse with her in her own idioglot language, although he also talked childish English.

We have endeavoured in the account of these idioglot children truthfully to record facts, and have added the conclusions which they seemed to warrant, but we feel far from being able to offer any satisfactory explanation of the infirmity from which these children suffer.

That it is congenital seems undoubted, it was noticed as soon as the children began to speak; this together with the fact that the worst case was the youngest in the family, makes it certain to our minds that it was not acquired by imitation.

It might seem to some that this is but a permanent form of domestic baby language; but a study of the tables will at once show that this is not the case, and also the vocabulary is too extensive. The resemblance of the language of these children in its form to English and the fact that they usually employ the proper number of syllables in each word, and further that they write correctly are arguments against the idea that idioglossia is an example of atavism in language.

In some of the few other cases which have been observed it has been noticed that the subjects of idioglossia are left-handed, or have their viscera transposed; it will be seen that the former defect was present in one of the children here described, but both defects may possibly be mere coincidences. 
A child similarly affected was shown to the Neurological Society last year by Dr. W. B. Hadden. This patient was almost cured by careful training. Romanes ('Mental Evolution in Man,' p. 138) quotes two cases from American literature. $\mathrm{He}$ brings them forward to show that children, like animals, will occasionally invent arbitrary signs constituting a language of their own, but he, like us, is unable to give any satisfactory explanation of the cases he mentions.

Romanes' cases are not analysed in detail and are merely quoted by him to illustrate special points which he is discussing. We believe that Dr. Hadden's cases and those which we bring before the Fellows of this Society, this evening, are the first in which full accounts of the infirmity and its progress have been given in this country. ${ }^{1}$

1 Since this paper was read other cases, under the title of "Formation of Language," have been recorded in 'Nature,' March 26th, 1891, p. 491, and April 9th, 1891, p. 534 .

(For report of the discussion on this paper, see ' Proceedings of the Royal Medical and Chirurgical Society,' Third Series, vol. iii, p. 95.) 